\title{
SUBJECTIVIDADE E INTERSUBJECTIVIDADE: SARTRE PERANTE HEGEL E HUSSERL
}

PEDRO M. S. Alves

\begin{abstract}
Resumo: Neste artigo, examino a teoria sartreana do conflito. Ela é a tese fundamental de Sartre no que se refere à descrição fenomenológica das relações interpessoais. Sublinho as dívidas de Sartre relativamente a Hegel e a Husserl, e sigo a evolução da tese sartreana desde La Transcendance de l'Ego até L'Être et le Néant. O artigo procura mostrar alguns dos problemas da Teoria do Conflito de Sartre. Primeiramente, há um problema no que diz respeito à maneira como Sartre focaliza suas descrições exclusivamente no relacionamento "face-a-face”. Em segundo lugar, há um outro problema no modo como Sartre tenta descrever a consciência de um alter-ego como um tipo de consciência de si ou de autoconsciência (a consciência de um alter-ego é, para Sartre, o mesmo que a consciência de si próprio como um "ser-para-o-outrem”), em vez de uma intenção direta no plano pré-reflexivo. Termino com uma apreciação negativa da tese de Sartre.
\end{abstract}

Palavras-chave: Sartre, Conflito, Fenomenologia, Consciência.

Em O Ser e o Nada, Sartre afirma em tese que o conflito é o elemento envolvente de todas as relações humanas. Conflito não significa, aí, uma simples confrontação de vontades, uma divergência quanto a crenças ou opiniões ou outro qualquer acontecimento ocasional, que pode ser sempre convertido no seu contrário. A tese de Sartre é, antes, que "o conflito é o sentido originário do ser-para-outrem". ${ }^{1}$ Isso é o mesmo que dizer que o sentido da relação de uma consciência com outra consciência é o conflito. Deste modo, aí onde o ser-para-si se prolonga no ser-paraoutrem, ou seja, aí onde surge para um sujeito a consciência de um outro que não está apenas diante dele na sua pura existência corpórea, mas que é uma outra subjectividade ou um outro ser-para-si, aí surgirá também o conflito como figura originária de sentido de toda e qualquer relação intersubjectiva. O conflito é, por isso, um ingrediente da constituição ontológica da realidade humana enquanto tal. Surpreendido nesta dimensão, todas as formas concretas de relação com outrem, que Sartre descreve minuciosamente em O Ser e o Nada, serão interpretadas como estratégias diversas de resolução deste conflito de base que emerge do próprio movimento pelo qual há para um sujeito consciência de um outro sujeito como não sendo ele. Mas não só. Todas as formas concretas da relação com outrem, que Sartre agrupa nos pares do amor e do masoquismo e do desejo e do sadismo e que

\footnotetext{
${ }^{1}$ « Le conflit est le sens originel de l'être-pour-autrui ». Sartre - L'être et le néant. Paris : Gallimard, 1943, p. 413.
}

Revista da Abordagem Gestáltica - XIII(1): 97-109, jan-jun, 2007 
analisa, em O Ser e o Nada, com a sua habitual finura psicológica e o seu também habitual excesso de palavras, todas essas figuras concretas são não só interpretadas como estratégias de resolução do conflito, como também analisadas até o ponto em que todas elas se mostram como conduzindo finalmente a um inevitável "échec", ou seja, a um inexorável fracasso. Assim, o conflito não é apenas o prius das relações humanas. Porque o fracasso é o resultado de todas as formas concretas de relação com outrem, o conflito é também o dado inextirpável e o sentido final de todas elas. Não porque sejam para o conflito, numa qualquer visão polemológica da existência, mas porque têm no conflito o seu elemento permanente e jamais resolúvel, seja numa comunidade finalmente apaziguada sob o signo do desejo ou do amor, seja na contra-imagem negativa de uma como que "anticomunidade", erguendo-se sobre as figuras da indiferença ou do ódio. Nesta medida, para Sartre, conflito e ser-para-outrem são conceitos equivalentes.

As posições de Sartre em O Ser e o Nada a respeito da intersubjectividade não se pretendem simples análises fenomenológicas realizadas numa asséptica posição de neutralidade descritiva. Tal neutralidade, que ele de resto não reclama, seria mesmo inteiramente questionável, pois o problema, com Sartre, não está tanto na descrição do objecto, mas no modo como o próprio objecto é disposto para a descrição. Apresentando-se como descrições fenomenológicas dos processos pelos quais há consciência de um outro sujeito e posição da sua existência, as análises de Sartre pretendem simultaneamente jogar no tabuleiro das doutrinas filosóficas. E, aí, o seu primeiro gesto é a recusa do ser-com, do Mitsein de Heidegger, como forma originária da consciência de outrem. É que, segundo Sartre, a análise do sentido da consciência de outrem mostra três coisas: ${ }^{2}$ primeiro, que o ser-para é mais fundamental que o ser-com de Heidegger; segundo, que o ser-com se desagrega numa consciência do nós-objecto (como quando dizemos "eles vêem-nos") e do nós-sujeito (como na expressão contrária “nós vemo-los"); terceiro, que o nós-objecto é redutível à estrutura do ser-para e que o nós-sujeito é um fenómeno psicológico sem consistência ontológica. ${ }^{3}$ Como o próprio Sartre afirma, "a imagem empírica que melhor simbolizaria a intuição heideggeriana não é a da luta, é a da equipa". ${ }^{4}$ Pelo privilégio do ser-com de Heidegger passaria a proeminência da comunidade sobre individualidade, da cooperação sobre a luta, do mútuo reconhecimento na comum pertença a um solo sobre a consciência solitária e desenraizada da liberdade. São precisamente essas as dimensões que Sartre secundariza na sua tese da precedência do ser-para relativamente ao Mitsein: "a essência das relações entre consciências não é o Mitsein, é o conflito". ${ }^{5}$

\footnotetext{
${ }^{2}$ Ver idem, pp. 464-482.

${ }^{3}$ « [...] l'expérience du nous-sujet est un pur événement psychologique et subjectif en une conscience, qui correspond à une modification intime de la structure de cette conscience mais qui n’apparaît pas sur le fondement d'une relation ontologique concrète avec les autres et qui ne réalise aucun « mitsein ». »Idem, pp. 476-477.

이 ${ }^{4}$ 《L'image empirique qui symboliserait le mieux l'intuition heideggerienne n'est pas celle de la lutte, c'est celle de l'équipe. »Idem, p. 292.

${ }^{5}$ «L'essence des rapports entre consciences n'est pas le Mitsein, c'est le conflit. »Idem, p. 481.
} 
Se a tese de Heidegger é rejeitada num gesto liminar, toda a análise da consciência intersubjectiva é, por outro lado, um diálogo cerrado com Husserl e Hegel. A leitura sartriana de Husserl está fixada desde o pequeno ensaio sobre $A$ Transcendência do Ego, publicado em 1936. Contra as teses husserlianas das Ideias, de 1913, Sartre sustenta a necessidade de uma dupla inflexão na fenomenologia. A primeira diz respeito ao seu "kantismo" residual. Em lugar do "inútil e nefasto" ego da consciência transcendental constituinte haveria antes que falar de um campo transcendental sem sujeito. A segunda inflexão diz respeito ao próprio modo como, para a fenomenologia husserliana, todo ser é supostamente reduzido a uma série de significações que se preenchem em actos intuitivos confirmando essas intenções significativas, de tal modo que toda a relação ao ser e toda e qualquer posição de existência - e, por isso mesmo, também a do ser de outrem - é, por princípio, entendida como um acto de conhecimento. Ora, do ponto de vista do preenchimento intuitivo de uma intenção significativa, o outro é, por definição, uma ausência. Se há uma consciência certa da presença de outrem para a minha própria consciência - e há-a indubitavelmente -, então, para Sartre, essa vinculação de outrem à minha consciência não pode ser entendida como um acto cognitivo. Tal é a segunda inflexão. Inflexões tão mais necessárias quanto esta orientação da fenomenologia de Husserl teria, segundo Sartre, um elevado preço a pagar. Nas suas próprias palavras: "ele [Husserl] não poderá, portanto, tanto quanto Kant, escapar ao solipsismo". ${ }^{6}$ De facto, a partir do momento em que outrem é uma significação na consciência de um ego transcendental, a preencher num acto intuitivo correspondente, e que o ser de outrem é, por definição, inacessível para o meu ego próprio, o solipsismo será o desfecho final e incontornável. Se a existência de outrem é um objecto de conhecimento, outrem não será jamais cognoscível e a posição da sua existência será para sempre uma simples probabilidade.

Em vivo contraste com Husserl, “a intuição genial de Hegel é de me fazer depender do outro no meu ser". 7 Assim, outrem não é um simples objecto para o meu ego, mas uma instância "indispensável [para] a própria existência da minha consciência enquanto consciência de si", "o ser-para-outrem aparece como uma condição necessária do meu ser para mim-mesmo". ${ }^{8}$ No entanto, a proximidade de Sartre relativamente a esta intuição seminal de Hegel é apenas o primeiro passo para a afirmação de uma distância ainda maior. As célebres páginas de A Fenomenologia do Espírito, de Hegel, sobre a dialéctica do senhor

\footnotetext{
${ }^{6}$ «Ainsi, pour avoir réduit l'être à une série de significations, la seule liaison que Husserl a pu établir entre mon être et celui d'autrui est celle de la connaissance ; il ne saurait donc, pas plus que Kant, échapper au solipsisme ». Idem, p. 280.

${ }^{7}$ « Ainsi l'intuition géniale de Hegel est ici de me faire dépendre de l'autre en mon être. »Idem, p. 282.

${ }^{8}$ « Ce n'est plus, en effet, à la constitution du monde et de mon « ego » empirique que l'apparition d'autrui est indispensable : c'est à l'existence même de ma conscience comme conscience de soi », "l'être-pour-autrui apparaît comme une condition nécessaire de mon être pour moi-même ». Idem, pp. 280 e 283, respectivamente.
} 
e do escravo arrancam do conflito e caracterizam-no como uma luta pelo mútuo reconhecimento da liberdade. É neste reconhecimento que a consciência devém autoconsciência. Toda a autoconsciência pode, assim, ser compreendida como mediada pela consciência de outrem e como assentando na posição do outro como lugar de reconhecimento da sua própria liberdade. É esta dialéctica interna do reconhecimento que desemboca na experiência da dominação e da servidão. Neste ponto relativo à origem profunda do conflito, a intuição de Hegel é inteiramente sobreponível na de Sartre. Mas qualquer leitor de A Fenomenologia do Espírito sabe que a luta pelo reconhecimento é, ao contrário do conflito sartriano, um momento desde sempre superado na passagem da autoconsciência subjectiva - que Hegel identifica com as figuras históricas do estoicismo e do cepticismo - às formas do espírito objectivo, tal como elas se plasmam no domínio eticidade. A cristalização do conflito como sentido permanente e final do afrontamento das liberdades marca, por isso, uma primeira distância de Sartre relativamente Hegel. E a segunda, que é tributária desta primeira, reside na suposta tentativa hegeliana, que Sartre longamente critica, de superar esse afrontamento conflitual das liberdades instalando-se no ponto de vista do Absoluto. Assim, a superação do conflito implicaria uma operação de transcensão da subjectividade individual para a totalidade e a invenção de um ponto de vista que já não seria concretamente reassumível por qualquer uma das subjectividades em conflito. A união conflitual dissipar-se-ia, certamente. Mas esse momento de superação seria também um ponto de fuga situado num plano que nenhum sujeito poderia já fazer seu. Contra esta suposta deriva hegeliana, Sartre reafirma que "o único ponto de partida possível é o cogito cartesiano", ${ }^{9}$ ou seja, a consciência subjectiva de si mesmo, na sua individualidade e facticidade mesmas. Daí o segundo distanciamento de Sartre relativamente a Hegel. Nas suas próprias palavras: “a multiplicidade dos “outrem” não poderá ser uma colecção, mas uma totalidade - nesse sentido, damos razão a Hegel porque cada outrem encontra o seu ser no outro; mas também que esta Totalidade será tal que é, por princípio, impossível colocarmo-nos "no ponto de vista do todo"." 10 É como se superação hegeliana do conflito não fosse jamais integrável na autoconsciência sob a forma do "para-mim".

Tais são, em breve súmula, as posições crítico-filosóficas que Sartre pretende extrair da sua tese de que o conflito é o sentido originário do ser-para-outrem. No espaço que nos resta, pretendemos submetê-las a uma apreciação. Em particular, tentaremos mostrar:

\footnotetext{
${ }^{9}$ «[...] l'échec de Hegel nous a montré que le seul départ possible était le Cogito cartésien ». Idem, p. 297.

${ }^{10}$ «Cela signifie d'abord que la multiplicité des « autrui » ne saurait être une collection mais une totalité - en ce sens nous donnons raison à Hegel - puisque chaque autrui trouve son être en l'autre ; mais aussi que cette Totalité est telle qu'il est par principe impossible de se placer « au point de vue du tout ». »Idem, p. 298.
} 
$1^{0}$. O sentido fenomenológico do próprio conflito, tal como Sartre o surpreende na passagem do ser-para-si ao ser-para-outrem.

$2^{\circ}$. O fracasso de Sartre na tentativa de contornar um suposto "escolho do solipsismo", com que Husserl se teria confrontado.

$3^{\circ}$. Em que sentido a lição hegeliana de uma reinserção das consciências na totalidade pode ser retomada, contra a opinião de Sartre, no prolongamento da fenomenologia da intersubjectividade numa fenomenologia da socialidade que permaneça ainda fiel ao ponto de partida do cogito cartesiano.

\section{II}

Falámos até agora do conflito, sem mais aprofundamentos e deixando, por isso, espaço aberto para a interpretação comum do significado desse fenómeno. É necessário, porém, compreender bem em que consiste e de onde emerge o conflito, enquanto forma de fundo do ser-para-outrem, pois, aqui, depara-se-nos um conjunto de teses que são, ao mesmo tempo, penetrantes análises fenomenológicas da dinâmica interna da existência humana e outras tantas interpretações controversas dessa mesma dinâmica que as análises tão finamente põem a descoberto. Desde logo, é necessário esclarecer o nível a que Sartre pretende localizar o fenómeno do conflito. Duas consciências simplesmente justapostas, ou seja, duas consciências que são duas não para si, mas apenas do ponto de vista de uma terceira, duas consciências que não se sabem mutuamente não estão ainda em conflito. Duas consciências que se tornam objecto uma para a outra não estão também ainda em qualquer tensão conflitual. O conflito emerge apenas quando uma consciência se confronta com o seu reflexo na consciência de outrem, ou seja, quando um sujeito toma consciência de si sob a forma da objectivação. O lugar desta relação mediata de si a si mesmo é precisamente o outro. O conflito é, assim, um fenómeno de terceiro nível - ele não provém da simples multiplicidade dos sujeitos, também não da consciência que cada um pode ter dos outros, mas da devolução, pela consciência de outrem, da imagem objectivada de si mesmo. Aí onde isso se verifica, aí emerge, para Sartre, o conflito.

Neste ponto preciso, duas coisas são importantes nas reflexões de Sartre a primeira é, desde logo, a identificação do fenómeno que marca a entrada em cena da tensão conflitual; a segunda é a razão por que, para Sartre, esta auto-objectivação mediada pela consciência de outrem terá de ser interpretada precisamente sob o signo do conflito.

Quanto à primeira, a resposta, célebre, de Sartre é a seguinte: a experiência original em que devenho consciente de mim tal como sou para outrem é o regard, o olhar. Não podemos entrar aqui num comentário dessas páginas de $O$ Ser e o Nada, que são um dos clássicos da descrição fenomenológica e um dos lugares em que Sartre mostra toda a sua finura analítica e o seu génio de psicólogo. Digamos apenas, em jeito de glosa, que o olhar do outro é invisível para mim. Posso ver os 
olhos de outrem percorrendo o espaço envolvente, posso vê-lo observando o espectáculo das crianças no jardim, as árvores e o lago ao redor, posso representar para mim o que ele está vendo do seu ponto de vista, posso acompanhar compreensivamente o seu olhar e segui-lo até o ponto em que, de objecto em objecto, se assesta sobre mim. A partir do momento em que me sei olhado, não posso ver o olhar de outrem porque, para mim, o olhar de outrem é uma actividade que me solicita passivamente enquanto visto. Acolher do olhar de outrem não é olhá-lo, é dar-se a ver. O olhar de outrem é, por natureza, algo que me invade e me penetra, me expõe e devolve numa relação modificada comigo mesmo. Eu já não sou soberano do meu mundo, pura transcendência, ou seja, $a$ consciência para a qual há objectos, mas transcendência esvaída na consciência de um outro, na medida em que eu e o meu ambiente circundante, os meus projectos e toda a relação instrumental com o mundo devêm objectos para outra consciência. Por aí, adquiro uma espécie de exterioridade, mas essa exterioridade é, porém, algo a que tenho de aderir, pois ela revela-me o meu próprio ser de um modo que antes não estava acessível para mim. Esse que o outro vê sou eu próprio, mas eu próprio a partir da exterioridade. Este novo ponto de vista marca um descentramento dramático na relação comigo mesmo. Não que eu exista doravante como uma coisa, pois não é como uma simples coisa que o olhar de outrem me descobre. Eu sou olhado, as coisas, essas, são simplesmente observadas. O olhar de outrem mantém-me ainda como uma transcendência, mas como uma transcendência transcendida, tal é a fórmula de Sartre. É como transcendência transcendida que o olhar me define. Nessa medida, o olhar de outrem é algo que eu jamais vejo, mas apenas sofro, e sofro-o na exacta medida em que ele me devolve a imagem objectivada do meu próprio ser. Poderei anular esta petrificação olhando por sua vez o outro. Mas, para Sartre, é impossível fazer coincidir de ambos os lados o momento da actividade - ou bem que olho ou bem que sou olhado, e o mesmo para o outro. É impossível que dois olhares se olhem, é impossível olhar o olhar de outrem sem o destruir.

Porquê este fenómeno do regard é fonte de conflito? Era essa a segunda questão. A resposta mais simples seria tentar surpreender uma diferença inultrapassável entre a consciência de si e a imagem de si próprio na consciência de outrem. O problema não está aí, porém. A consciência que outrem tem de mim próprio não é uma simples "imagem”, relativamente à qual poderia pretender que não coincide com a "realidade" daquilo que sou, uma realidade que só eu conheceria na intimidade da minha autoconsciência. Nada disso - outrem não tem uma imagem de mim, tem consciência do meu ser. O problema é, por isso, infinitamente mais fundo. Captar-me captando a consciência que outrem tem de mim ou o modo como sou para outrem levanta, para Sartre, um problema que não está no jogo da autoimagem e da contra-imagem, mas na pequena palavra ser. Pelo olhar de outrem, enquanto tenho consciência de mim próprio como visto, eu adquiro a consistência de um ser, adquiro uma natureza fixa e determinável, numa palavra, a estrutura ontológica do para-si altera-se dramaticamente: eu devenho um ser que é sob a forma do em-si. Sartre di-lo impressivamente em O Ser e o Nada: "Mas este ser 
[enquanto visto por outrem], a vergonha revela-me que eu o sou. Não sob o modo do haver-sido ou do "ter a ser", mas em-si. [...] Uma vez mais, o em-si se forma de novo sobre o para-si. Mas, uma vez mais, esta metamorfose se opera a distância: para o outro, eu estou sentado como este tinteiro está sobre a mesa: para o outro, estou inclinado sobre o buraco da fechadura tal como esta árvore está inclinada ao vento. Assim, eu despojei-me para o outro da minha transcendência, [...] eu tenho um exterior, uma natureza, a minha queda original é a existência de outrem". ${ }^{11}$ As adjectivações sartrianas desta alteração profunda da estrutura ontológica da realidade humana falam por si: "outrem alienou-me do meu mundo", "ser visto implica a alienação do mundo que eu organizo", "o outro é a morte escondida das minhas possibilidades enquanto eu próprio vivo essa morte", "o meu ser para-outrem é uma queda, [...] e esta queda é alienação". ${ }^{12}$

A génese do conflito pode agora ser compreendida: para Sartre, toda a dinâmica da existência humana é uma tensão de auto-recuperação, pela qual o existente humano procura a equação impossível entre ser e ser ao mesmo tempo consciência do seu ser. Essa tensão fracassa já na consciência pré-reflexiva. Esta é, simultaneamente, consciência posicional de um objecto e consciência de si enquanto consciência de tal objecto. Poderíamos dizer que nada separa estas duas consciências. A lição de Sartre é que o nada as separa. Este néant entre a consciência de algo e consciência (não-tética) de ser consciência cava uma distância de si a si. É essa distância, vivida já no plano pré-reflexivo, que a reflexão pretende colmatar. Mas, mais uma vez, para Sartre, a reflexão fracassa nesse desígnio de coincidência e de igualdade sem fissura. ${ }^{13}$ No entanto, agora, uma dupla negação separa a consciência do seu próprio ser - não apenas a negação que a separa no interior de si mesma, na distância originária de si a si, mas a negação que a separa de uma outra consciência que está posta como não sendo ela. ${ }^{14}$ A tensão de auto-recuperação tem, pois, diante de si a liberdade de outrem como obstáculo a superar. A relação com outrem, pensada a partir desta dinâmica profunda da existência humana, será, assim, a tentativa de absorver a liberdade de outrem, de agir sobre ela e de a incorporar. Esta tentativa permanente de absorção da liberdade de outrem é a estrutura de fundo da relação intersubjectiva. Toda a relação intersubjectiva se determina como um agir sobre a liberdade de outrem. É justamente por isso que, para Sartre, o sentido

\footnotetext{
${ }^{11}$ « Mais cet être, la honte me révèle que je le suis. Non pas sur le mode de l'étais ou du « avoir à être », mais en-soi. [...] Mais, une fois de plus, cette métamorphose s'opère à distance : pour l'autre, je suis assis comme cet encrier est sur la table; pour l'autre, je suis penché sur le trou de la serrure, comme cet arbre est incliné sur le vent. Ainsi ai-je dépouillé, pour l'autre, ma transcendance. [...] J'ai un dehors, j'ai une nature ; ma chute originelle c'est l'existence de l'autre. » Idem, pp. 308-309. ${ }^{12}$ Idem, pp. 307, 309, 311, 321, respectivamente.

${ }^{13}$ Cf. Idem, pp. 190 e sgs.

${ }^{14}$ « Ainsi, la réflexion comme effort de récupération d'un pour-soi par un pour-soi [...] est un stade de néantisation intermédiaire entre l'existence du pour-soi pur et simple et l'existence pour autrui comme acte de récupération d'un pour-soi par un pour-soi qu'el n'est pas sur le mode du n'être-pas. »Idem, p. 194.
} 
originário do ser-para-outrem é o conflito: “o meu projecto de recuperação de mim é, fundamentalmente, projecto de reabsorção do outro. [...] Seria, portanto, necessário [...] agir sobre a negação interna pela qual outrem transcende a minha transcendência e me faz existir para outrem, ou seja, agir sobre a liberdade de outrem" - "a unidade com outrem é, portanto, irrealizável. [...] e este projecto de unificação é fonte de conflito". ${ }^{15}$ A reabsorção de outrem é, ao mesmo tempo, necessária e impossível - necessária porque assim o exige a tensão fundamental do existente humano para a recuperação de si próprio, impossível porque ela choca com a alteridade de outrem e com uma tensão simétrica que a anula. Este échec é o próprio conflito, enquanto sentido originário da relação intersubjectiva.

Desta interpretação sartriana da estrutura de fundo da relação intersubjectiva, por mais sugestiva que ela seja, resultam, em minha opinião, dois paradoxos estreitamente ligados. O primeiro poderia ser formulado assim: o que vemos no outro não é a sua alteridade, mas o modo como somos para ele - toda consciência de um outro sujeito é, assim, ainda um captar-me a mim próprio pela captação de uma outra consciência para a qual sou objecto. É como se o outro, na sua alteridade própria, permanecesse invisível - tenho consciência do outro na medida em que ele é portador de uma consciência de mim mesmo, e é isso que fundamentalmente nele vejo. Tudo o resto se ergue sobre este fundamento. $\mathrm{O}$ segundo paradoxo depende do primeiro. Ele poderia ser assim formulado: o outro sujeito não parece ser, agora, uma outra consciência que está diante de mim, mas apenas o sentido da minha autoconsciência enquanto ela é auto-objectivação do meu próprio ser. É como se o sentido “outro sujeito" fosse equivalente à consciência da minha auto-objectivação, é como se o sentido "outro" fosse ainda um momento e um elemento da estrutura do meu próprio ser. De facto, eu sei-me sujeito para o mundo. Mas posso também representar-me como objecto nesse mundo para o qual sou sujeito. Tudo se passa como se o sentido "outro" fosse a projecção deste movimento de auto-objectivação. Poder-se-ia replicar que é por ocasião da consciência de outrem que se produz essa auto-objectivação - se o outro não fosse já dado na sua existência, esse processo não teria possibilidade de ocorrer. Mas isso é incorrecto, e é-o também aos olhos do próprio Sartre. Para ele, é antes o inverso que se passa - a auto-objectivação é a constituição originária do sentido "outro sujeito", antes mesmo da percepção de uma outra subjectividade particular. É justamente por isso que Sartre afirma que o "outro" é, originalmente, um sentido único e não plural, antes de ser a consciência da existência concreta deste ou daquele sujeito particular. ${ }^{16}$ A limite, mesmo que estivéssemos solitários no mundo, o sentido "outro" surgiria

\footnotetext{
${ }^{15}$ « Ainsi, mon projet de récuperation de moi est fondamentalement projet de résorption de l'autre [...] Il serait donc nécessaiere [...] d'agir sur la négation interne par quoi autrui transcende ma transcendance et me fait exister pour l'autre, c'est-à-dire d'agir sur la liberté d'autrui », « L'unité avec autrui est donc, en fait, irréalisable. [...] Ce projet d'unification est source de conflit ». Idem, pp. 414 e 415.

${ }^{16}$ Cf. Idem, p. 327 e sgs.
} 
pelo processo de auto-objectivação. Por isso, ele aparece aqui como algo redutível a uma estrutura da subjectividade. Ora como lançar com isto as bases de uma efectiva teoria da intersubjectividade? Sartre percebe-o lucidamente num passo de O Ser e o Nada: "Mas, dir-se-ia, não se trata simplesmente de que o olhar de outrem é o sentido da minha objectividade-para-mim? Por essa via, recairíamos no solipsismo: assim que me integrasse como objecto no sistema das minhas representações, o sentido desta objectivação seria projectado fora de mim e hipostasiado como outrem. "17 As longas explicações de Sartre para contornar esta dificuldade insistem na diferença entre sentido de uma experiência e condição de possibilidade de uma experiência. Outrem não seria o sentido da minha autoobjectivação, mas a sua condição. Ora isso significa que, se não fosse dado o facto da sua existência, não poderia jamais tornar-me objecto para mim próprio. Mas esta conclusão tem um elevado preço a pagar, que Sartre aceita sem hesitação: “o ser-para-outrem não é uma estrutura ontológica do Para-si. [...] Não seria talvez impossível conceber um Para-si totalmente livre de todo e qualquer Para-outrem e que existiria sem mesmo suspeitar da possibilidade de ser objecto. Simplesmente, este Para-si não seria um "homem”."18 O ser-para-outrem., por todo lado apresentado como a terceira dimensão do para-si e como elemento da estrutura ontológica da realidade humana, é aqui, contraditoriamente, expulso da constituição ontológica dessa realidade como um facto contingente. No entanto, e em sentido contrário, a possibilidade permanente da auto-objectivação faz da categoria "outrem" um ingrediente essencial da realidade humana. Tudo se passa como se um certo apriorismo, que faz do sentido "outro sujeito" um momento da consciência de si mesmo, fosse ao mesmo tempo expressamente negado por Sartre e reintegrado sub-repticiamente por esta concepção de que consciência de outrem e consciência objectivada de si próprio são, no fundo, conceitos coincidentes. Tal é o alto preço a pagar por esta dificuldade, que provém do próprio modo como a consciência da alteridade é desde o início compreendida.

Em nossa opinião, este duplo paradoxo faz da resposta sartriana ao pretenso escolho do solipsismo, em que Husserl teria embatido, uma falsa resposta e uma pseudo-solução.

Recuemos um pouco. Em A Transcendência do Ego, Sartre nega a tese de que o eu esteja formal ou materialmente na consciência. A consciência pré-reflexiva não diz “eu”. O eu está antes no mundo, é um ser mundano tanto quanto o eu dos outros. Certamente que o eu é dado à consciência transcendental como íntimo.

\footnotetext{
${ }_{17}$ « Mais, dira-t-on, n'est-ce pas simplement que le regard d'autrui est le sens de mon objectivité pour-moi ? Par là nous retomberions dans le solipsisme : lorsque je m'intégrerais comme objet au système concret de mes représentations, le sens de cette objectivation serait projeté hors de moi et hypostasié comme autrui. ». Idem, p. 319.

${ }^{18}$ « [...] l'être-pour-autrui n'est pas une structure ontologique du Pour-soi. [...] Il ne serait peut-être pas impossible de concevoir un Pour-soi totalement libre de tout Pour-autrui et qui existerait sans même soupçonner la possibilité d'être un objet. Simplement ce Pour-soi ne serait pas « homme ». »Idem, p. 329.
} 
Mas isso não significa que ele seja o sujeito da consciência. Segundo Sartre, o campo transcendental de que fala a fenomenologia de Husserl deve ser caracterizado como impessoal, ou melhor, como pré-pessoal, ou seja, sem eu. O eu é, como as outras coisas do mundo, um objecto para a consciência. Ele é uma unidade noemática, não uma unidade noética. A consciência é um absoluto, na medida em que é consciência si enquanto consciência de um objecto. Mas este "si" da consciência refere uma distância pré-reflexiva que ainda não é a diferença entre um eu e os seus actos. Trata-se de uma distância entre, por exemplo, crença e consciência de crença, uma distância que é constitutiva da própria consciência irreflectida. Como Sartre dirá mais tarde, a consciência está à distância de si própria por uma diferença que é um néant. Assim, toda consciência é consciência do seu objecto e de si própria enquanto consciência desse objecto. Tal é o plano préreflexivo. A reflexão que Sartre designa como "impura” é o lugar de constituição do ego. É o acto reflexivo que põe por vez primeira um eu por detrás do acto reflectido a título de seu sujeito. O ego é, assim, constituído, na reflexão impura, como sujeito dos estados e qualidades (trata-se do Moi) e das acções (trata-se do Je). Esta constituição do eu como ponto virtual de unidade do psiquismo é, por outro lado, o momento em que a consciência denega a sua própria liberdade e se compreende como um ser, que tem as suas propriedades fixas, as suas qualidades, os seus estados, as suas acções e a sua história pessoal. A constituição do eu é, por isso, uma estratégia de fuga à angústia de uma liberdade "monstruosa", "insuportável", que caracterizaria a consciência enquanto existente absoluto, sem porquê e sem razão.

Segundo Sartre, esta teoria resolveria definitivamente o problema do solipsismo com que a fenomenologia egológica de Husserl se teria confrontado. Pois não se trataria já de saber como é que um eu conhece um outro eu, mas apenas de mostrar que eu próprio e eu alheio estão ambos no mundo como objectos da consciência absoluta e que são tão certos um como o outro. Mas isto não resolve o problema, como Sartre bem viu em O Ser e o Nada. Pelo contrário, aprofunda-o e torna-o intratável. Pois agora é o próprio campo transcendental pré-pessoal de cada consciência que é absolutamente solitário e sem mediação possível com outro campo transcendental. Um eu pode aparecer e ser apreendido por outrem. Mas um campo transcendental puro é uma interioridade que, por definição, não tem exterioridade.

Contra esta solução demasiado optimista de A Transcendência do Ego, Sartre vê nas análises do ser-para-outrem de O Ser e o Nada uma resposta finalmente satisfatória ao problema. No entanto, vista de perto, esta nova posição de Sartre é estruturalmente idêntica à que havia sido desenvolvida em $A$ Transcendência do Ego. Ela continua a ver a génese do sentido "outro sujeito" como algo que surge no prolongamento da reflexão. Assim, o sentido "outro" é ainda e sempre reconduzido à consciência de si. Ora isto é uma base incorrecta para uma teoria da intersubjectividade, pois a consciência de um outro sujeito é algo que não depende da reflexão e que lhe é mesmo anterior. O próprio Sartre admite que o ser-paraoutrem é compreendido, em O Ser e o Nada, na extensão da reflexão e como uma 
espécie de reflexão na segunda potência: "a ec-stase reflexiva encontra-se a caminho de uma ec-stase mais radical: o ser-para-outrem. [...], [...] nesta terceira ec-stase, assistimos a algo como uma cissiparidade reflexiva mais desenvolvida, [...] o ser para outrem parece ser o prolongamento da pura cissiparidade reflexiva”. ${ }^{19}$ Deste modo, o processo de auto-apreensão como um ser e de denegação da liberdade não é apenas característico da reflexão impura. Ele conhece na posição do outro o seu momento conclusivo. Não é apenas para mim que me constituo como um ser - é na consciência de outrem que esse processo de cousificação alcança o seu acabamento final. Assim, a consciência de outrem é puro prolongamento da reflexão, ela apenas intensifica a dualidade reflexiva e acrescenta-lhe uma segunda negação interna.É precisamente por isso que, como vimos, Sartre pode, sem a sombra de uma hesitação, tratar a consciência de outrem como se ela fosse equivalente à consciência de mim próprio para uma outra consciência, ou seja, como se o outro fosse apenas uma ocasião e um suporte para a consciência de mim mesmo. Em boa verdade, o que vemos não é o outro, mas o nosso reflexo especular nele. Ter consciência de um outro sujeito é, sartrianamente, vermo-nos pela hipóstase de uma outra consciência. Que a relação intersubjectiva seja um perpétuo jogo de espelhos, que, na captação de um outro sujeito, apenas nos seja devolvida uma vez mais apenas a nossa própria imagem numa última degradação, ou seja, como objecto, eis o resultado pouco satisfatório, mas, contudo, inevitável da compreensão sartriana da dinâmica da intersubjectividade. Nesta teoria, a invisibilidade do outro é total. Dissemos atrás que acolher o olhar de outrem era dar-se a ver. Sabemos agora o que é, para Sartre, este dar-se a ver: é consciência de si enquanto visto, o outro é convocado como mediador de mim próprio. O sentido "outro" é apenas o ponto virtual que sustenta esse derradeiro olhar sobre mim mesmo. Ele é uma ocasião, e a consciência é a solidão do soi-même e das múltiplas reverberações desse seu ser - primeiro, na cissiparidade reflexiva, depois, na cissiparidade intersubjectiva. E porque a cissiparidade intersubjectiva não pode ser reunificada sem uma reabsorção da liberdade de outrem que o destruiria na sua alteridade, eis o conflito que emerge como fundo permanente de todas as relações humanas. A consciência de si é o círculo em que fatidicamente sempre nos encerramos. Apesar da sua implausibilidade prática, a hipótese do solipsismo tem toda a dignidade teórica para uma filosofia da consciência. Há que mostrar por que razão sabemos sempre que há outros sujeitos. Mas que dizer de uma teoria que nos deixa sós no meio dos outros, de uma teoria para a qual a nossa consciência dos outros, que povoam o nosso mundo, nos devolve, no fundo, as infinitas reverberações do nosso próprio ser? Aqui, o solipsismo deixou de ser uma hipótese com que toda e qualquer teoria terá honestamente de se confrontar. Ele é uma forma de vida. Há duas questões de natureza diversa de que uma teoria da intersubjectividade se deve ocupar. Uma é:

\footnotetext{
${ }^{19}$ « Ainsi l'ek-stase réflexive se trouve sur le chemin d'une ek-stase plus radicale : l'être-pourautrui. [...] Dans le cas de la troisième ek-stase, nous assistons comme à une scissiparité réflexive plus poussée. [...] L'être pour autrui paraît être le prolongement de la pure scissiparité réflexive. » Idem, pp. 346 e 347.
} 
como é que vejo um outro sujeito e tenho a certeza da sua existência? Outra é: como é que me vejo na consciência que tenho de um outro sujeito? Sartre respondeu à segunda crendo que respondia à primeira. Daí todas as ambiguidades e insuficiências da sua posição.

É justamente por isso que a teoria sartriana da intersubjectividade se revela incapaz de produzir uma teoria da socialidade. É já um sintoma disso o facto de Sartre, quando passa para as questões que envolvem a consciência socializada de um "nós”, não ter outra coisa para oferecer senão uma retomada do marxismo. Esta aproximação poderia parecer natural: uma teoria do conflito intersubjectivo lança mão de uma teoria do conflito social. No entanto, o problema está em que a dialéctica da intersubjectividade é a alternância entre ter o outro como objecto da minha consciência ou ser objecto na consciência de outrem. Esta alternância não pode jamais ser superada. O meu mundo é objecto para outro ou o mundo do outro é objecto para mim, mas jamais nos guindamos, eu e outrem, à consciência de um mundo comum, para o qual ambos sejamos sujeitos. Ora os processos de socialização do ego são precisamente esses actos em que intersubjectivamente se constitui um mundo comum, cujo sujeito já não é o "eu” em oposição a um "ele”, mas o "nós”. É precisamente essa dimensão que Sartre corta cerce, ao recusar quer a originalidade do Mitsein de Heidegger quer a deriva hegeliana para o ponto de vista da totalidade. No entanto, a fenomenologia do mundo social é um projecto teórico desenvolvido em trabalhos como o do fenomenólogo Alfred Schütz, contemporâneo de Sartre. A impossibilidade da fenomenologia produzir uma teoria da constituição intersubjectiva do mundo social não é uma interdição que se abata sobre a fenomenologia enquanto tal. Ela é apenas o último preço a pagar pela ideia sartriana de que o ser-para-outrem é a forma originária da relação intersubjectiva e que, neste para-outrem, somos, fundamentalmente, ainda e uma vez mais prisioneiros de um projecto de recuperação de nós próprios.

Numa peça célebre (Huis-Clos), Sartre confessou que l'enfer, c'est les autres. Pedindo desculpa pela ousadia, diria que, em Sartre, verdadeiramente, l'enfer, c'est le moi. 
Abstract: In this paper, I examine conflict theory as the fundamental thesis of Sartre's phenomenological description of interpersonal relationships. I stress Sartre's debts toward Hegel and Husserl, and I follow his evolution from La transcendance de l'ego till L'être et le néant. I intend to show several problems in Sartre's conflict thesis. First, there is a problem regarding the way Sartre focuses his descriptions exclusively on the face-to-face relationship. Second, there is another problem regarding Sartre's attempt to describe the relation to an alter ego as a kind of self-consciousness (consciousness of an alter ego is the same as self-consciousness as a "being-for-other"), instead of a direct intention in the pre-reflexive area. I finish with a negative appraisal of Sartre's thesis.

Keywords: Sartre, Conflict, Phenomenology, Consciousness.

Resumen: En este articulo, examino la teoría del conflicto de Sartre. Esta es la tesis fundamental de Sartre en lo que se refire a la descripción fenomenológica de las relaciones interpersonales. Dando enfasis en las influencias de Hegel y Husserl sobre Sartre, sigo la evolución de la tesis sartreana desde La Transcendance de l'Ego hasta L'Être et le Néant. El articulo apresenta algunos de los problemas de la Teoria del Conflicto de Sartre. En primer lugar tenemos el problema de la manera como Sartre foca sus descripciones en la relación de uno a otro. En segundo lugar, tenemos el problema de la descripción de la consciência de un alter-ego como una consciência de si o autoconsciência (la consciência de un alter-ego es, para Sartre, lo mismo que la consciência de si-mismo como un "serpara-el-otro"). El texto finda con la apreciación negativa de la tesis de Sartre.

Palabras-Clave: Sartre, Conflicto, Fenomenología, Consciéncia.

Pedro M. S. Alves: Doutor em Filosofia; Professor da Faculdade de Letras da Universidade de Lisboa; Diretor da Revista Phainómenon (Revista de Fenomenologia); Presidente da Associação Portuguesa de Filosofia Fenomenológica (APOFFEN); Atualmente coordena um projeto de tradução de clássicos da Fenomenologia, aprovado pelo Centro de Filosofia da Universidade de Lisboa. 